\title{
The Relationship between Self-determination, Expectancy-Value Beliefs and Future Time Perspective
}

\author{
Fariba Faghihi $^{1 *}$, Morteza Chemelnezhad ${ }^{2}$ \\ 1. Sistan and Baluchestan University, Zahedan, Iran. \\ 2. Ma in History and Philosophy of Education, Payame Noor University of Tehran, Tehran, Iran \\ * Corresponding author's Email: f.faghihi94@gmail.com
}

\begin{abstract}
The aim of this study is to investigate the relationship between self-determination, expectation-value beliefs and future time perspective in high school students. To this purpose, 186 high school students ( 88 boys and 98 girls) are selected by stratified random sampling. The research tools include: Expectancy-Value Questionnaire, Basic Psychological Needs Scale and Future Time Perspective Scale. For data analysis, one sample t-test, independent samples t-test and Pearson correlation coefficient are used. Results indicate that participants in self-determination and its dimensions (autonomy, competence, and communication), value expectation and its dimensions (except the component of understanding the difficulty of the task) and the future time perspective and its components (except the component of focus on opportunity), have a higher score than average. Also, it is revealed that there is a positive and significant relationship between self-determination and expectancy-value beliefs, but there is no significant relationship between self-determination and future time perspective. According to the results, there is a significant difference between the male and female students in self-determination, but there is no significant difference between the two groups in the expectancy-value beliefs and future time perspective.
\end{abstract}

Keywords: Self-determination, expectancy-value beliefs, future time perspective

\section{Introduction}

One of the most important goals of the education system, which has always been considered by researchers, is to nurture motivated, purposeful, progressive and efficient learners. The knowledge of psychology, especially in the field of motivation and learning, based on its research findings, has played the greatest role in advancing this path and has always had great achievements in identifying and understanding human behavior as well as improving his abilities. The concept of motivation has always been considered by human societies, especially researchers and education specialists. In recent decades, many theorists of educational psychology have given special importance and place to the motivational and psychological patterns of academic behavior (Pintrich, 2000). Psychologists have concluded that a set of internal and external factors, variables or structures are involved in motivating a person to learn and actively participate in the educational process, including: instinct, driver, need, enthusiasm, and curiosity, all of which can influence students' motivation system in a complex interaction and shape their educational behavior, learning and development (Fatima, Sharif, \& Zimet, 2018). On the other hand, teachers are always looking for appropriate ways to help convince their students that what they are learning is useful and practical for their lives. Although there are many theories and exercises to choose from, teachers do not have enough time to use them all in their teaching or in the classroom. Therefore, in recent years, the issue of motivation in the educational system and educational process of students has attracted many educational psychologists' attention (Rezaei Gazki, Delavar, \& Samavi, 2019).

One of the motivational approaches that has attracted a lot of attention in recent years is the theory of

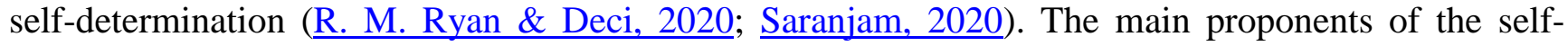


determination theory (SDT) are Desi and Ryan (1985). This model claims that the motivation process should consider three important constructs: "intrinsic motivation", "external motivation" and "lack of motivation" (Wu \& Li, 2019). The best form of self-determined activity arises from intrinsic motivation, in which the motivation to participate in an activity for pleasure is due to the activity itself without any goals or results (R. M. Ryan \& Deci, 2020). On the other hand, when a person works to achieve something that is outside of his activity, it is called external motivation. Demotivation, which is the third type of motivation, occurs when there is no internal or external motivation. This is usually equated with what is called "learned helplessness". The theory of self-determination assumes that there are three basic psychological needs for fostering effective mental development: autonomy, competence, and communication ( R. M. Ryan \& Deci, 2020). Autonomy is the tendency to be self-initiated and the cause and source of one's behavior in performing activities rather than being controlled by external factors. Autonomy is a set of learned behaviors and skills that enable a person to make decisions and solve problems (W. S. Ryan \& Ryan, 2019). Competence is the ability to perform challenging tasks and being effective in interacting with the environment (Wang, Liu, Kee, \& Chian, 2019); in fact, it creates the necessity of the desire to seek challenging situations for the individual. In those situations, the person gets the opportunity to acquire skills and by practicing these skills, he / she affects his / her environment and feels capable. Communication is also about people feeling connected to and supported by others (Jacobi, 2018). The three basic psychological needs are interrelated. Communication provides the safety needed for people to start self-centering. Feeling self-centered in doing jobs increases competence. Competence provides the necessary trust to feel accepted and dependent on the environment (Goldman, Goodboy, \& Weber, 2017; Zilka, 2018). If the basic psychological needs are satisfied, a sense of worthiness is formed in people, but if these needs are prevented and not satisfied, the person develop a fragile, negative, alien and critical perception of himself (Chen \& Jang, 2010).

Deci (2009), as the founder of the theory of self-determination, states that human beings may be motivated by an inherent and internal attraction to do a task or by the use of reward and punishment but they cannot be affected by both at the same time. Those who are motivated from within are likely to be deeply involved and fascinated by the work, or it seems that this activity has fascinated and overwhelmed them (Oldervik \& Lagestad, 2021).

In the field of education, research has shown that basic and psychological needs have a positive and significant relationship with students' relationships, student-teacher relationships, and normative expectations and educational opportunities (Froiland, Worrell, \& Oh, 2019). It has also been found that the psychological needs of autonomy and competence have a direct positive and significant effect on students' intrinsic motivation (Goldman et al., 2017). In addition, according to Ryan and Deci's theory of self-determination (2008), the basic concept that can explain the relationship between students' satisfied psychological needs and their experiences in the classroom is independence and autonomy. The size of one's goals is completely voluntary and independent; the extent to which students pursue their goals completely voluntarily and independently, and also, to what extent do they feel competent in pursuing goals and maintain their positive relationships with others in this process (Ntoumanis, 2001). It is also the latest theory about needs; it has been tested mostly in students of individualistic societies and paid attention to intrinsic motivation. Therefore, few research has been done in this field in Iran. Therefore, the present study, in addition to theoretically helping to develop the theory of selfdetermination and testing it in Iranian students who have more collectivist culture, also has practical applications. Good performance in school, homework and different areas of study are valuable for success in society, and predicting outcomes during the school and adolescence years is useful and important for educational policymakers and researchers. 
In Pulyaeva and Nevryuev (2020) study, the relationship between basic psychological needs satisfaction (autonomy, competence and communication) and academic motivation (internal, external and lack of motivation) with academic achievement has been investigated; the results showed there is a significant and positive relationship between basic psychological needs and academic achievement.

The results of Ejei, Khezri azar, Babaei sangelaji, and Amani (2009) study conduct to investigate the relationship between the perception of autonomy support by the teacher, basic psychological needs (autonomy, competence and communication), intrinsic motivation and effort by modeling structural equations; it shows that autonomy support by the teacher has a positive and significant direct effect on meeting psychological needs and thereby indirectly affects students' intrinsic motivation. Also, the psychological needs of autonomy and competence have a positive and significant direct effect on students' intrinsic motivation. But communication effect on students' intrinsic motivation is not significant. Intrinsic motivation has a direct and positive effect on students' effort. In general, it can be concluded that pro-autonomy environments meet the basic psychological needs and thus increase students' intrinsic motivation.

Moltafet, Sadati Firoozabadi, and Pour-Raisi (2018) in their research investigated the relationship between parental styles and emotional creativity and investigated the mediating role of the fulfillment of basic psychological needs in this relationship and concluded that the components of parenting style could predict students' emotional creativity.

One of these consequences of self-determination is the motivation for achievement (Slavin, 2012). The expectancy-value models associated with achievement motivation have a long history (Wigfield \& Eccles, 2000). The new expectancy-value theory is one of the most effective motivational theories that incorporates the expectation and value components. This theory has been proposed by Wigfield and Eccles (2000) and has introduced different components for predicting achievement-related behaviors. Among the most important components are task value, ability-expectation beliefs and understanding task difficulty (Flake, Barron, Hulleman, McCoach, \& Welsh, 2015). Task value is defined as the motivation to engage in different activities and students' various reasons for doing or ignoring them; it deals with encouraging task for individuals (Flake et al., 2015). Another component is expectancy. Ability self-concept refers to students' beliefs about how well they perform in different activities. But expectancy reflects a person's beliefs and judgments about his or her ability to do a task and its success. The self-concept of ability is focused on the present ability, while the expectancy is focused on ability in the future (Flake et al., 2015). Understanding the task difficulty is also considered as students' understanding of the difficulty / complexity of the task (Flake et al., 2015). Atkinson and Shiffrin (1968) predicted that whenever task difficulty is moderate, motivation will reach its peak. Ability-expectation beliefs in academic subjects and other subjects predict excellence, pleasure, and success, and so when a task is presented and a person has higher ability-expectation beliefs, he or she is motivated for that task which leads to progressive behaviors. And this is how the importance of ability-expectation beliefs is demonstrated. Collectively, belief-expectation and task-value beliefs play an important role for expectancy-value theory, which is one of the major theories today (Wigfield \& Eccles, 2000).

Research on expectancy-value models shows the importance of ability-expectation beliefs for task selection, engagement, learning and efficiency; an important generalization of these studies has been obtained. Students who have positive ability expectations and beliefs have better performance and learning, and they adaptively do academic tasks. For example, they are more persistent and more cognitively involved in the task (Rosenzweig, Wigfield, \& Eccles, 2019). 
In their field research, Wigfield and Eccles (2000) concluded that the value component, that is, the student's understanding of the importance and application of the task and interest in it, is a better predictor of the intention to pursue specific courses and decide to enroll in them.

In addition to the expectancy-value model, which emphasizes the characteristics of the task, other motivation theories also emphasize the importance and characteristics of the task, especially focusing on the future consequences of the task that lead to the adaptive approach. This assumption is extended to the Future time perspective (FTP). Future perspective theory points to the importance of the personal future in current motivation and learning (Kooij, Kanfer, Betts, \& Rudolph, 2018). FTP is a motivational-cognitive concept that is formed as a result of setting motivational goals. FTP means predicting future goals at present. People with short FTP set their goals in the near future, and people with long FTP set their goals over a longer distance (Rohr, John, Fung, \& Lang, 2017). Long-term goals can be achieved by setting goals and placing intermediate goals in the long-term goal range (Henry, Zacher, \& Desmette, 2017). Xie, Debacker, and Ferguson (2006) suggest that the amount of time people perceive is related to motivation, and this perception of time varies with age. Thus, young people have the ability to predict farther and older people have less ability to predict. The relationship between future perspective and motivation variables based on past research includes: future perspective is related to severe involvement in task and study, perseverance, deep learning and intrinsic motivation (Barnett, Melugin, \& Hernandez, 2020). Shell and Husman (2001) concluded that future perspective beliefs play an important role in achievement motivation and study.

In De Bilde, Vansteenkiste, and Lens (2011) study of high school and college students, students with deep FTP found that their study behavior was based on several internal motivations, including guilt and shame (embedded rules), regulate personal belief and interest (intrinsic motivation). In addition, embedded rules and personal beliefs played a mediating role in the relationship between FTP and cognitive processing. The relationship between FTP and the theory of self-determination is also discussed in this study.

Students are more involved in school with external factors related to positive future goals and they achieve better grades (Rowley, 2000). Therefore, the present study is conducted to investigate the relationship between self-determination with expectation-value theory and future time perspective in students.

According to the above, the following questions are answered in the present study:

1 - What is the status of students in terms of self-determination?

2- What is the status of students in terms of expectancy-value?

3- What is the status of students in terms of future time?

4. Is there a relationship between self-determination and expectancy-value?

5. Is there a relationship between self-determination and the future perspective?

6. Is there a significant difference between students' self-determination, expectancy-value, and future time perspective with respect to gender?

\section{Material and Methods}

The research method used in this research is descriptive and correlational. The statistical population of the present study includes all male and female students of the third grade of secondary school in the city of Jinnah, Iran, with a volume of 361 people in the academic year 2016-2017. The sample size is determined based on Morgan table to 186 people ( 88 boys, 98 girls) who are selected by stratified random sampling method. After randomly selecting the subjects, the questionnaires are presented to 
them individually at the rest time and after collecting, the obtained data are analyzed by SPSS 16 software.

\section{Research tools}

Expectancy-value questionnaire (EVQ): This researcher-made questionnaire is designed based on expectancy-value theory and has the following subscales: ability-expectation beliefs: 6 questions of this scale are based on the following researches: 4 questions from Eccles and Wigfield (1995), 1 question from Pintrich (2000); 1 question from Watt, Eccles, and Durik (2006). Students mark their answer on a 7 -point Likert scale $(1=$ very bad to $7=$ very good). The total score of this scale is obtained by calculating the mean of the questions (Simpkins \& Davis-Kean, 2005). Simpkins and Davis-Kean (2005) estimates the validity of this scale with 3 questions in science and 5 questions in mathematics as 0.91 and 0.92, respectively. Watt et al. (2006) report a Cronbach's alpha of .80 in the Australian sample with 3 questions and .88 in the American sample with 4 questions. In the present study, the reliability of this component is estimated to be .83 .

Understanding the task difficulty: 4 questions of this scale are based on the research of Eccles, O'Neill, and Wigfield (2005). Students mark their answers on a 7-point Likert scale. (1 = very easy to 7 = very hard). The score of this scale is obtained by average calculation of items. Eccles et al. (2005)report a validity of this scale of .80. In the present study, the validity of this subscale is .67.

Task value: 6 questions of this scale are based on the following researches: 4 questions from the research of (Eccles et al., 2005); 1 question from Welch Deal (2003); and 1 question from Watt et al. (2006). Answers are based on a 7 -point Likert scale ( $1=$ very useful to $7=$ very useless). The score of this scale is obtained by calculating the average of items (Simpkins \& Davis-Kean, 2005). Simpkins and DavisKean (2005) report the validity of this scale with 4 questions in science course (alpha 0.88) and 7 questions in mathematics course (alpha .89). In the study of Liem, Lau, and Nie (2008), in English, the validity of task value with 4 questions is .78. In the present study, the validity of this scale is calculated to be .78 .

Basic Psychological Needs Questionnaire: This scale is developed by the La Guardia, Ryan, Couchman, and Deci (2000) to measure the sense of support for autonomy, competence and connection with other subjects. The scale consists of 21 items based on the seven-point Likert scale. The reliability coefficients obtained from its performance on mother, father, romantic partner and friends of the subjects have been reported as .92 ((La Guardia et al., 2000). In Iran, this scale has been implemented in the samples of Iranian administrators and students and has a good validity and reliability. So, the alpha fluctuates between .74 and .79 (Ejei et al., 2009). In the present study, an alpha of .77 has been obtained for it.

Future Perspective Questionnaire: This is a 10-item questionnaire designed by Carstensen and Lang (1966) (Jung, Park, \& Rie, 2015) and includes two subscales (focusing on opportunities and focusing on constraints). Focusing on constraints is measured by the first three questions being scored inversely, and focusing on opportunities is measured by the last seven questions (Betts, 2013). Participants answer questions on a scale from $(1=$ completely correct $)$ to $(7=$ completely incorrect $)$. In the present study, the validity of this scale is calculated as .60 .

\section{Results}

In this section, the findings obtained from the statistical tests of the present study are reviewed:

What is the status of students in terms of self-determination?

One-sample t-test is used to determine the status of students in terms of self-determination. 
Table 1. Results of one sample t-test to assess students' self-determination

\begin{tabular}{|l|l|l|l|l|l|l|}
\hline Variable & M & SD & test T & Test value & DF & $\boldsymbol{p}$ \\
\hline Autonomy & 34.03 & 7.03 & 11.69 & 28 & 185 & .001 \\
\hline Competence & 29.09 & 5.86 & 11.83 & 24 & .001 \\
\hline Communication & 40.26 & 7.71 & 14.61 & 32 & 185 & .001 \\
\hline Self-determination & 103.39 & 16.51 & 16 & 84 & 185 & .001 \\
\hline
\end{tabular}

According to the findings of the table 1, the autonomy component of the self-determination dimensions has an average of 34.03 which is higher than the test average, which is significant with the t-value calculated at the $99 \%$ confidence level. Finally we can say that autonomy component is higher than average. And it means that students feel independent in performing their academic duties. Also, in examining the competency component according to table 1 , it is found that most of the students surveyed feel effective competence in their activities. Also, the component has a higher mean than the test mean. The need for communication involves another and have the friends' supports; the environment of the classroom indicates the relationship with other students. Finally, according to the findings (Table 1) and the relevant interpretations, such a conclusion can be made. Students are above average in terms of selfdetermination and its dimensions; this means that most of the students surveyed have the ability to choose their tasks and activities.

\section{What is the status of students in terms of expectancy-value?}

One-sample t-test was used to assess students' expectancy-value status.

Table 2. Expectancy-value status of students

\begin{tabular}{|c|c|c|c|c|c|c|}
\hline Variable & M & SD & T test & Test value & Df & Sig \\
\hline Ability-expectation beliefs & 31.67 & 5.53 & 18.89 & 24 & 185 & .001 \\
\hline Understanding the difficulty of the task & 15.73 & 4.13 & -.88 & 16 & 185 & .37 \\
\hline Task value & 34.15 & 5.58 & 24.80 & 24 & 185 & .001 \\
\hline Value expectation & 81.55 & 9.35 & 25.59 & 64 & 185 & .001 \\
\hline
\end{tabular}

The findings of the table 2 indicate that the beliefs of ability-expectation from the components of expectancy-value with the mean of 31.67 and $t=18.89$ at the level of $99 \%$ are significant, and this means that most of the students have the ability and necessary qualifications to succeed in their assigned task. On the other hand, the results of Table 2 indicate that the task comprehension component with an average of 15.73 is lower than the test average, and this indicates that most students are not in a good position in terms of the task comprehension component. Findings also show that in relation to the task value component, most of the students surveyed are above the average, and thus it can be concluded that most students give different reasons for the task they do, including the interesting and useful task. Finally, the results of the table 2 show that the expectancy-value of $t=25.59$ and a freedom degree of 185 , is significant at the level of $99 \%$. Based on the above findings, it is concluded that the expectancy-value level in students is higher than the average level. Based on this, it is perceived that students are in a favorable status in terms of this variable. 


\section{What is the status of students in terms of future perspective?}

One-sample t-test is used to assess the status of students based on the future time perspective variable.

Table 3. Future time perspective status in students

\begin{tabular}{|l|c|c|c|c|c|c|}
\hline Variable & M & SD & T test & Test value & DF & $\boldsymbol{p}$ \\
\hline Focusing on constraints & 17.31 & 3.09 & 23.38 & 12 & 185 & .001 \\
\hline Focusing on opportunities & 27.20 & 6.94 & -1.55 & 28 & 185 & .12 \\
\hline Future perspective & 44.52 & 7.13 & 8.64 & 40 & 185 & .001 \\
\hline
\end{tabular}

According to the data in Table 3, the following results are obtained. The variable focusing on constraints calculates $\mathrm{T}$ as 23.38 and degree of freedom as 185 , which is significant at the level of $99 \%$. Accordingly, the component of focusing on constraints is above average. Therefore, it means that most students focus more on the constraints and feel the many boundaries that prevent them from achieving their academic achievement in achieving future goals. The component of focusing on opportunities from the future perspective has an average of 27.20 and a degree of freedom of 185, below average; Based on this, it can be concluded that most of the students surveyed do not have a positive perception of the future and do not pursue future goals. But the results of the table 3 indicate that the future time perspective is significant with a mean of 44.52, which is greater than the mean (Test value $=40$ ), and a degree of freedom of 185 and $t=8.64$ at the level of $99 \%$ confidence. Therefore, in general, it can be said that most students are in a favorable status in terms of future time perspective.

\section{Is there a relationship between self-determination and expectancy-value?}

Pearson correlation coefficient is used to investigate the relationship between self-determination and expectancy-value.

Table 4. Correlation matrix between self-determination variable and expectancy-value variable

\begin{tabular}{|c|c|c|c|c|c|c|c|c|}
\hline Variable & 1 & 2 & 3 & 4 & 5 & 6 & 7 & 8 \\
\hline 1. Self determination & 1 & & & & & & & \\
\hline 2. Competence & $.51 * *$ & 1 & & & & & & \\
\hline 3. Communication & .14 & $.64 * *$ & 1 & & & & & \\
\hline 4. $\quad$ Self-determination(general) & $.64 * *$ & $.25 * *$ & $.21 * *$ & 1 & & & & \\
\hline 5. Task value & $.47 * *$ & $.58 * *$ & .12 & $.48 * *$ & 1 & & & \\
\hline 6. Ability expectation beliefs & $.18 * *$ & $.36 * *$ & $.38 * *$ & $.51 * *$ & $.24 *$ & 1 & & \\
\hline 7. Understanding of task difficulty & $.23 * *$ & $.61 * *$ & $.24 * *$ & $.77 * *$ & .031 & .12 & 1 & \\
\hline 8. Expectation-value & $.77 * *$ & $.41 * *$ & .13 & $.53 * *$ & $.27 * *$ & $.20 * *$ & $.31 * *$ & 1 \\
\hline
\end{tabular}

The findings of Table 4 indicate that in general, the variable of self-determination with expectancy-value at the level of $99 \%$ has a positive and significant relationship. Also, the components of autonomy and competence have a positive relationship with three dimensions of expectancy-value (task value, abilityexpectation beliefs and task difficulty perception), which is significant. The communication component has also established a positive and significant relationship at the $99 \%$ level with the beliefs of abilityexpectation and task difficulty understanding, from the dimensions of expectancy-value theory; it has no significant relationship with the task-value component. 


\section{Is there a relationship between self-determination and the future perspective?}

Pearson correlation coefficient is used to investigate the relationship between self-determination and future time perspective.

Table 5. Correlation matrix between self-determination variable and future time perspective variable

\begin{tabular}{|c|l|l|l|l|l|l|l|}
\hline Variable & 1 & 2 & 3 & 4 & 5 & 6 \\
\hline $1 . \quad$ Autonomy & 1 & & & & & \\
\hline 2. Competence & $.52^{* *}$ & 1 & & & & & \\
\hline 3. Communication & $.24^{* *}$ & $.64^{* *}$ & 1 & & & & \\
\hline $4 . \quad$ Self-determination(total) & $.64^{* *}$ & $.25^{* *}$ & $.21^{* *}$ & 1 & & \\
\hline $5 . \quad$ Focusing on constraints & .025 & $.31^{* *}$ & .12 & $-.21^{* *}$ & 1 & & \\
\hline $6 . \quad$ Focusing on opportunities & .10 & $.90^{* *}$ & $.07^{*}$ & $.50^{* *}$ & $.20^{* *}$ & 1 \\
\hline $7 . \quad$ Future time perspective & .15 & $.61^{* *}$ & $.33^{* *}$ &. $\mathbf{0 9}$ & $.28^{* *}$ & $.90^{* *}$ \\
\hline$* * .01$
\end{tabular}

The results of Table 5 show that self-determination has no significant relationship with the future time perspective. Also, the results indicate that some components of self-determination include autonomy and communication have no significant relationship with any of the components of the future time perspective.

6. Is there a significant difference between students' self-determination, expectancy-value, and future time perspective with respect to gender?

Independent samples t-test was used to compare the research variables based on gender variable.

Table 6. Comparison of research variables by gender index

\begin{tabular}{|c|c|c|c|c|c|c|c|}
\hline Variable & Sex & $\mathbf{N}$ & Mean & Mean difference & DF & T Value & $p$ \\
\hline \multirow{2}{*}{ Self-determination } & Male & 88 & 103.15 & \multirow{2}{*}{5.23} & \multirow{2}{*}{184} & \multirow{2}{*}{2.18} & \multirow{2}{*}{.03} \\
\hline & Female & 98 & 100.91 & & & & \\
\hline \multirow{2}{*}{ Expectancy-value } & Male & 88 & 81.17 & \multirow{2}{*}{-.73} & \multirow{2}{*}{184} & \multirow{2}{*}{-.53} & \multirow{2}{*}{.5} \\
\hline & Female & 98 & 81.90 & & & & \\
\hline \multirow{2}{*}{ Future time perspective } & Male & 88 & 45.46 & \multirow[b]{2}{*}{1.79} & \multirow[b]{2}{*}{184} & \multirow[b]{2}{*}{1.72} & \multirow[b]{2}{*}{.18} \\
\hline & Female & 98 & 43.67 & & & & \\
\hline
\end{tabular}

According to Table 6, according to the value of $t$ obtained, the degree of freedom and the level of significance listed in the table 6 for each of the variables, the evidence shows that there is a statistically significant difference between the mean variable of male and female students self-determination. On the contrary, the two groups do not show a significant difference in terms of expectancy-value and FTP. This means that students are the same in terms of expectancy-value and future time perspective variables based on gender.

\section{Discussion}

The aim of this study is to investigate the relationship between self-determination with expectancy-value theory and future time perspective in students. The results show that there is a positive and significant relationship between self-determination with expectancy-value theory and future time perspective. Also, some components of self-determination include: autonomy and competence with the three dimensions of expectancy-value, i.e., task value, ability-expectation beliefs and task difficulty perception have a positive and significant relationship at $99 \%$ level. However, the relationship between the relationship component and ability-expectation beliefs and task difficulty understanding is significant at the $99 \%$ level; but it has no significant relationship with the task value component. Although no research has 
been conducted that directly examines the relationship between the dimensions of self-determination and the expectation-value dimension. The results of the present study suggest (Deci \& Ryan, 2008)) that humans may be motivated by a task because of their innate attraction; those who are aroused from within are likely to be deeply involved with and fascinated by work. This finding is also consistent with some of the results of earlier studies (Badri, Amani-Saribaglou, Ahrari, Jahadi, \& Mahmoudi, 2014; Pulyaeva \& Nevryuev, 2020) which show that the satisfaction of basic psychological needs is related to motivation for academic achievement. Because the ability-expectation beliefs in academic courses predict excellence, pleasure, and success. When a task is presented and the person has higher ability-expectation beliefs, he or she is motivated by the task and develops progressive behaviors.

Also the results of research by Eccles and Wigfield (2002)) have been concluded by the value component, i.e. the student's understanding of the importance and application of the task and interest in it is a better predictor of the intention to continue certain courses and the decision to enroll in these courses which supports the results of the present study.

Analysis of the results of the present study also shows that there is no significant relationship between self-determination and its components and the future perspective. Analysis of the correlation between the dimensions of these two variables also shows that some components of self-determination include: autonomy and communication have no significant relationship with any of the components of the future perspective, but the relationship between the competency component and focusing on constraints are negative significant, but its relationship with focusing on opportunities has become positive and significant. The overall conclusion of this finding is not consistent with the results of Rowley (2000). In this regard, it can be pointed out that the teaching method and educational process, as well as the content of school textbooks are prepared in such a way that most students believe that these materials are not useful for their life and future. This matter as well as the working conditions of the community cause frustration in students, and as a result, students who become frustrated with learning show less motivation and effort.

The findings of the present study also indicate that there is a statistically significant difference between the mean variable of male and female students in the self-determination variable, and since boys in the present study have higher levels of self-determination than girls, these findings are consistent with the research of Lauderdale, Yli-Piipari, Irwin, and Layne (2015); they conclude in their study that in general the degree of satisfaction of basic psychological needs in men are higher than women. In interpreting this finding, it can be said that having freedom of action in the field of education makes students feel more committed to their academic performance, and their attention and desire are more spent on expanding knowledge and skills for others' approval. Especially in this study, where the participants are in the age range of adolescence, gaining independence is more important. On the other hand, meeting the need for communication in students, which arises from having a favorable relationship with classmates, teachers and parents, reduces the tendency to overtake others in competition and excellence and causes students to compare their academic achievement with themselves alone and focus more on understanding the subjects, without comparing themselves with others or for fear of not understanding the subject or receiving a low grade. Also, people whose competence needs have been satisfied, believe in their competence and ability to influence the environment and having effective interactions with the social environment; they seek opportunities to practice and express their abilities, so it is less likely that these people worry about not understanding and mastering the concepts and topics of the lesson. According to research, whenever the level of support for the need for autonomy, competence and communication has been greater, and strongly supports boys and men, it is not surprising that boys' basic psychological needs (autonomy, competence, and communication) are satisfied more than girls'. 
In addition, the results show that students are in a good position in terms of value expectation and its dimensions, including ability-expectation and task value, but in terms of understanding task difficulty, the average of the students are lower than the average of the test. Also, despite numerous studies, no research has ever examined the status of individuals in terms of expectations-value and its dimensions. Explaining this result, it can be said that students participate more in valued tasks, and they have different reasons for interacting in the task. They believe they can do their tasks. They are more cognitively involved in the task, more diligent, and spending more time on the task. But they are not in a good position to understand the difficulty of the task.

On the other hand, the present findings show that students are in a good position in terms of overall FTP and their average in FTP is higher than the test average. But besides the components, the findings show that the average of students in the component of focusing on constraints is higher than the average, but in the component of focusing on opportunities, conflicting results have been obtained. Explaining the above findings, it can be concluded that according to the 10-item future perspective questionnaire, which is graded on a seven-point Likert scale, people who get a high score in the constraint dimension have a lower FTP, but those who get a high score in the opportunity dimension have a higher FTP. Accordingly, the students surveyed have lower FTP because they have higher scores in the constraint dimension. In this field, no research have been accomplished, compared to the above results.

The results obtained in this study in the framework of theories of self-determination, expectancy-value and future perspective, are considered as a kind of link between these theories. In fact, the results of this study are a relatively new model of the relationship between self-determination and motivational factors which shows the value and perspective of the future in students. The results therefore help to expand these theories.

Relying on the findings of this research, it is suggested that in designing and compiling curricula for high school, in addition to paying attention to the development of cognitive dimensions, special attention should be paid to the emotional dimensions and psychological needs of students. Also, It is suggested that teachers in their classrooms provide meaningful materials related to real life situations. They give learners as much freedom as possible in their educational activities. Furthermore, it is suggested that teachers design tasks is a challenging way regarding the students' capabilities so that students gain experience of mastery and success in doing tasks, which helps students to achieve a relatively accurate but high perception of competence and to avoid believing in their incompetence. Teachers cultivate the belief in students that grades are not a measure of competency, and encourage them to learn deeply. By using appropriate educational methods and mastering the subjects, they should create opportunities for students to learn and give them the pleasure of learning.

The results of this research have some limitations related to the questionnaire. Furthermore, since the society under study are students, the findings of this study cannot be generalized to other groups.

Conflict of interest: The authors state no conflict of interest in the study.

Financial sponsor: The authors acknowledge that they have not received any financial support for all stages of the study, writing and publication of the paper. 
Acknowledgment: We hereby appreciate all the participants of the study as well as all those participating in the implementation of this project.

\section{References}

Atkinson, R. C., \& Shiffrin, R. M. (1968). Human memory: A proposed system and its control processes. In Psychology of learning and motivation (Vol. 2, pp. 89-195): Elsevier.

Badri, R., Amani-Saribaglou, J., Ahrari, G., Jahadi, N., \& Mahmoudi, H. (2014). School culture, basic psychological needs, intrinsic motivation and academic achievement: Testing a casual model. Mathematics Education Trends and Research, 4, 1-13.

Barnett, M. D., Melugin, P. R., \& Hernandez, J. (2020). Time perspective, intended academic engagement, and academic performance. Current Psychology, 39(2), 761-767.

Betts, M. J. (2013). Future time perspective: examination of multiple conceptualizations and workrelated correlates. Georgia Institute of Technology,

Chen, K.-C., \& Jang, S.-J. (2010). Motivation in online learning: Testing a model of self-determination theory. Computers in Human Behavior, 26(4), 741-752.

De Bilde, J., Vansteenkiste, M., \& Lens, W. (2011). Understanding the association between future time perspective and self-regulated learning through the lens of self-determination theory. Learning and instruction, 21(3), 332-344.

Deci, E. L. (2009). Large-scale school reform as viewed from the self-determination theory perspective. Theory and research in education, 7(2), 244-252.

Deci, E. L., \& Ryan, R. M. (2008). Self-determination theory: A macrotheory of human motivation, development, and health. Canadian psychology/Psychologie canadienne, 49(3), 182.

Eccles, J. S., O’Neill, S. A., \& Wigfield, A. (2005). Ability self-perceptions and subjective task values in adolescents and children. In What do children need to flourish? (pp. 237-249): Springer.

Eccles, J. S., \& Wigfield, A. (1995). In the mind of the actor: The structure of adolescents' achievement task values and expectancy-related beliefs. Personality and social psychology bulletin, 21(3), 215225.

Eccles, J. S., \& Wigfield, A. (2002). Motivational beliefs, values, and goals. Annual review of psychology, 53(1), 109-132.

Ejei, J., Khezri azar, H., Babaei sangelaji, M., \& Amani, J. (2009). A Structural Model of the Relationships between the Perceived Teacher Autonomy Support, Basic Psychological Needs, Intrinsic Motivation, and Effort. Research in Psychological Health, 2(4), 47-56.

Fatima, S., Sharif, H., \& Zimet, G. (2018). Personal and social resources interplay synergistically to enhance academic motivation. International Journal of Educational Psychology, 7(2), 196-226.

Flake, J. K., Barron, K. E., Hulleman, C., McCoach, B. D., \& Welsh, M. E. (2015). Measuring cost: The forgotten component of expectancy-value theory. Contemporary Educational Psychology, 41, 232244.

Froiland, J. M., Worrell, F. C., \& Oh, H. (2019). Teacher-student relationships, psychological need satisfaction, and happiness among diverse students. Psychology in the Schools, 56(5), 856-870.

Goldman, Z. W., Goodboy, A. K., \& Weber, K. (2017). College students' psychological needs and intrinsic motivation to learn: An examination of self-determination theory. Communication Quarterly, 65(2), 167-191.

Henry, H., Zacher, H., \& Desmette, D. (2017). Future time perspective in the work context: A systematic review of quantitative studies. Frontiers in Psychology, 8, 413.

Jacobi, L. (2018). What motivates students in the online communication classroom? An exploration of self-determination theory. Journal of Educators Online, 15(2). 
Jung, H., Park, I.-J., \& Rie, J. (2015). Future time perspective and career decisions: The moderating effects of affect spin. Journal of Vocational Behavior, 89, 46-55.

Kooij, D. T., Kanfer, R., Betts, M., \& Rudolph, C. W. (2018). Future time perspective: a systematic review and meta-analysis. Journal of Applied Psychology, 103(8), 867.

La Guardia, J. G., Ryan, R. M., Couchman, C. E., \& Deci, E. L. (2000). Within-person variation in security of attachment: a self-determination theory perspective on attachment, need fulfillment, and well-being. Journal of personality and social psychology, 79(3), 367.

Lauderdale, M. E., Yli-Piipari, S., Irwin, C. C., \& Layne, T. E. (2015). Gender differences regarding motivation for physical activity among college students: A self-determination approach. The Physical Educator, 72(5).

Liem, A. D., Lau, S., \& Nie, Y. (2008). The role of self-efficacy, task value, and achievement goals in predicting learning strategies, task disengagement, peer relationship, and achievement outcome. Contemporary Educational Psychology, 33(4), 486-512.

Moltafet, G., Sadati Firoozabadi, S. S., \& Pour-Raisi, A. (2018). Parenting style, basic psychological needs, and emotional creativity: A path analysis. Creativity Research Journal, 30(2), 187-194.

Ntoumanis, N. (2001). Empirical links between achievement goal theory and self-determination theory in sport. Journal of sports sciences, 19(6), 397-409.

Oldervik, S., \& Lagestad, P. (2021). Importance of Providing Additional Choices in Relation to Pupils' Happiness, Mastery, Well-Being, Contentment, and Level of Physical Activity in Physical Education. Frontiers in Sports and Active Living, 3, 84.

Pintrich, P. R. (2000). The role of goal orientation in self-regulated learning. In Handbook of selfregulation (pp. 451-502): Elsevier.

Pulyaeva, V., \& Nevryuev, A. (2020). The relationship of basic psychological needs, academic motivation and alienation from study of students in higher education. Psychological science and education, 25(2), 19-32.

Rezaei Gazki, P., Delavar, A., \& Samavi, A. (2019). Does Academic Commitment Affect the Learners' Progress through Academic Buoyancy? A Structural Equation Model. Iranian Evolutionary and Educational Psychology Journal, 1(3), 196-203.

Rohr, M. K., John, D. T., Fung, H. H., \& Lang, F. R. (2017). A three-component model of future time perspective across adulthood. Psychology and Aging, 32(7), 597.

Rosenzweig, E. Q., Wigfield, A., \& Eccles, J. S. (2019). Expectancy-value theory and its relevance for student motivation and learning. In K. A. Renninger \& S. E. Hidi (Eds.), The Cambridge handbook of motivation and learning (pp. 617-644): Cambridge University Press.

Rowley, S. J. (2000). Profiles of African American college students' educational utility and performance: A cluster analysis. Journal of Black Psychology, 26(1), 3-26.

Ryan, R. M., \& Deci, E. L. (2020). Intrinsic and extrinsic motivation from a self-determination theory perspective: Definitions, theory, practices, and future directions. Contemporary Educational Psychology, 61, 101860.

Ryan, W. S., \& Ryan, R. M. (2019). Toward a social psychology of authenticity: Exploring withinperson variation in autonomy, congruence, and genuineness using self-determination theory. Review of General Psychology, 23(1), 99-112.

Saranjam, R. (2020). Psychometric Properties of Self-Regulating Climate Questionnaire. Iranian Evolutionary and Educational Psychology Journal, 2(2), 120-130.

Shell, D. F., \& Husman, J. (2001). The multivariate dimensionality of personal control and future time perspective beliefs in achievement and self-regulation. Contemporary Educational Psychology, 26(4), 481-506.

Simpkins, S. D., \& Davis-Kean, P. E. (2005). The intersection between self-concepts and values: Links between beliefs and choices in high school. New Directions for Child and Adolescent Development, 2005(110), 31-47. 
Slavin, R. E. (2012). Educational psychology: Theory and practice. Boston: Allyn \& Bacon.

Wang, C. J., Liu, W. C., Kee, Y. H., \& Chian, L. K. (2019). Competence, autonomy, and relatedness in the classroom: understanding students' motivational processes using the self-determination theory. Heliyon, 5(7), e01983.

Watt, H. M., Eccles, J. S., \& Durik, A. M. (2006). The leaky mathematics pipeline for girls: A motivational analysis of high school enrolments in Australia and the USA. Equal Opportunities International.

Welch Deal, M. R. (2003). Gender differences in expectancy of academic success in mathematics. (MA), University of Wisconsin-Stout, Wisconsin-Stout.

Wigfield, A., \& Eccles, J. S. (2000). Expectancy-value theory of achievement motivation. Contemporary Educational Psychology, 25(1), 68-81.

Wu, Y., \& Li, C. (2019). Helping others helps? A self-determination theory approach on work climate and wellbeing among volunteers. Applied Research in Quality of Life, 14(4), 1099-1111.

Xie, K., Debacker, T. K., \& Ferguson, C. (2006). Extending the traditional classroom through online discussion: The role of student motivation. Journal of Educational Computing Research, 34(1), 6789.

Zilka, G. C. (2018). Why do children and adolescents consume so much media? An examination based on self-determination theory. Global Media Journal, 16(30), 1-10.

\footnotetext{
@ $(\mathbb{Q} \Theta$

EY NC This work is licensed under a Creative Commons Attribution-Noncommercial 4.0 International License
} 